\title{
Associations among gender, coping patterns and functioning for individuals with chronic pain: A systematic review
}

\author{
Nina El-Shormilisy BSc MPhil(C), Jenny Strong PhD MOccThy BOccThy, Pamela J Meredith PhD BA(Hons) BSc BOccThy
}

N El-Shormilisy, J Strong, PJ Meredith. Associations among gender, coping patterns and functioning for individuals with chronic pain: A systematic review. Pain Res Manag 2015;20(1):48-55.

BACKGROUND: Developing strategies for coping with chronic pain is an integral part of successfully living with this often debilitating health condition. While gender differences in pain coping strategies have long been investigated, the relationship between gender-specific engagement in coping and associated functioning in individuals experiencing chronic pain is yet to be clearly understood.

OBJECTIVE: The present systematic review focused on studies that address these relationships to critically evaluate the available evidence. METHODS: A systematic search was conducted using MEDLINE via Ovid, EMBASE, PsycINFO and CINAHL, with 7247 titles retrieved. To be included, studies had to be in English, focus on adult participants, consider chronic nonmalignant pain, use measures of coping and functioning (or disability), report on gender-specific outcomes (for coping and functioning [or disability]), and investigate a relationship among gender, coping and functioning. One researcher screened abstracts and full-text articles, and extracted and tabulated data, while two researchers independently assessed potential articles for eligibility and methodological quality. RESULTS: Only seven studies met the inclusion criteria - six of high quality and one of moderate quality. The presented findings suggest that women in pain are more likely to use coping strategies considered to be maladaptive, resulting in poorer functioning, while men tend to engage in coping strategies considered to be adaptive, leading to better functional outcomes.

CONCLUSIONS: While there is some evidence supporting genderspecific engagement in coping and associated functioning, future research is necessary to expand understanding of these interrelations.

Key Words: Chronic pain; Coping; Disability; Functioning; Gender; Sex; Systematic review

\section{Les associations selon les sexes, les modes d'adaptation et le fonctionnement des personnes ayant des douleurs chroniques : une analyse systématique}

HISTORIQUE : Pour bien vivre avec la douleur chronique, qui est sou-
vent débilitante, il est essentiel de se doter de stratégies pour y faire face. Les
différences dans les stratégies d'adaptation à la douleur selon le sexe font
l'objet de recherches depuis longtemps, mais le lien entre l'investissement
dans l'adaptation et le fonctionnement connexe selon le sexe chez les per-
sonnes qui souffrent de maladies chroniques est encore mal compris.
OBJECTIF : La présente analyse systématique portait sur des études axées
sur ces liens afin de procéder à une évaluation critique des données proban-
tes disponibles. MÉTHODOLOGIE : Les chercheurs ont effectué une recherche systématique à l'aide de MEDLINE dans Ovid, EMBASE, PsycINFO et CINAHL et en ont extrait 7247 titres. Pour être incluses, les études devaient être rédigées en anglais, porter sur des participants adultes, traiter de douleurs chroniques non cancéreuses, faire appel à des mesures d'adaptation et de fonctionnement (ou d'incapacité), rendre compte de résultats propres au sexe (sur l'adaptation et le fonctionnement [ou l'incapacité]) et examiner le lien entre le sexe, l'adaptation et le fonctionnement. Un chercheur a analysé les résumés et les versions intégrales des articles, en a extrait et colligé les données, tandis que deux chercheurs ont procédé à une évaluation indépendante des articles pour en déterminer l'admissibilité et la qualité méthodologique.

RÉSULTATS : Seulement sept études respectaient les critères d'inclusion. Six étaient de haute qualité et une, de qualité modérée. D'après les observations présentées, les femmes qui souffrent sont plus susceptibles de recourir à des stratégies d'adaptation considérées comme mésadaptées, qui s'associent à un moins bon fonctionnement, tandis que les hommes ont tendance à adopter des stratégies considérées comme adaptatives, qui donnent de meilleurs résultats fonctionnels.

CONCLUSIONS : Certaines données probantes appuient l'investissement dans l'adaptation et le fonctionnement connexe selon le sexe, mais des recherches plus approfondies s'imposent pour mieux comprendre ces interrelations.

successful in only approximately one-half of individuals living with chronic pain, even after completing multidisciplinary rehabilitation programs $(14,15)$. After completion of these programs, women in particular appear to have difficulties in maintaining achieved successes to support their functioning in life; one study has shown that they frequently returned to their preintervention levels of catastrophizing, while men did not (16). This suggests that gender differences are still not well understood and gender-differentiated treatment requires more attention.

With the growing awareness of gender effects on coping and function in a chronic pain population, much research has been conducted in the recent years. Some differences in functioning and pain management behaviours between men and women with chronic pain have been documented (17-20); however, there are inconsistencies. treatment of people in pain. This is highlighted by the fact that long term pain relief and return to work have been documented to be

School of Health and Rehabilitation Sciences, The University of Queensland, St Lucia, Queensland, Australia

Correspondence: Ms Nina El-Shormilisy, The University of Queensland, St Lucia, Queensland 4072, Australia. Telephone 61-478-973-444,

e-mailn.elshormilisy@uq.edu.au 
While some results indicate that women and men are similar in their coping attempts $(21,22)$ and level of functioning $(23,24)$, others have observed gender differences in both coping $(21,25,26)$ and functioning $(21,27,28)$. Besides considerable research on these individual correlations, the more complex relation among all three terms of interest has received less attention. Men and women differ in their pain experience, with biological factors, such as differences in hormone levels, posited as one reason for these differences $(21,29)$. However, other than biological reasons, gender differences in pain may also be related to psychosocial factors such as symptom reporting patterns (28).

The present systematic review was motivated by a need to provide guidance for future research and to highlight gaps and inconsistencies in the available literature. The particular focus has been chosen to promote better understanding of gender differences in pain behaviour. This, in turn, will guide the development and provision of the best possible treatment for each individual patient.

This systematic review addresses two goals: to review current knowledge about associations among gender, coping patterns and functioning in the face of chronic pain; and to provide directions for further research and clinical approaches.

\section{METHODS}

Inclusion criteria

To be included in the present systematic review, studies needed to be written in English, focus on adult participants ( $\geq 18$ years of age), consider chronic nonmalignant pain (duration of $>3$ months), include a measure of coping/pain management strategies, include a measure of functioning (including activity, participation and/or disability), report gender-specific outcomes (ie, gender differentiation of coping/pain management and functioning) and investigate a relationship among these three variables (gender, coping and functioning). The focus was on associations among gender, coping and functioning in adults only because the heterogeneity of a mixed sample of adults and minors would confound findings due to different role participation in adulthood and childhood that determine functioning in daily living.

Articles focusing on malignant or experimental pain studies were excluded, as was research focusing on case or single-sex studies. No restrictions regarding publication dates were imposed.

It has been suggested that the results with the most generalizability are obtained from studies using a randomized controlled trial or longitudinal research design $(30,31)$, because they have the highest external validity. However, these studies are less frequently found in the literature, perhaps due to the resources required to perform such studies. For this reason, no specific restrictions were placed on the nature of the quantitative research designs included in the present review (32).

\section{Search strategy}

Studies were obtained by searching electronic databases, in addition to manually scanning reference lists and bibliographies of retrieved articles. The following databases were searched up to November 2012: PsycINFO (1880 to present), MEDLINE via Ovid (1950 to present), EMBASE (1966 to present) and CINAHL (1982 to present). Combinations of key words and synonyms were used to conduct a broad search: ('chronic pain' OR 'chronic' OR 'persisting' OR 'enduring') AND ('gender' OR 'sex') AND ('adult' OR 'adulthood') AND ('cope' OR 'coping' OR 'coping strategies' OR 'pain management' OR 'deal with' OR ‘dealing with' OR 'live with' OR 'living with') AND ('active' OR 'activity' OR 'activities' OR 'activeness' OR 'participate' OR 'participation' OR 'participating' OR 'disability' OR 'disabilities' OR 'disabled' OR 'disabling' OR 'impairment' OR 'inability' OR 'functioning' OR 'performance').

Both 'gender' and 'sex' were included as search terms due to the lack of clarity in the use of these terms, especially in older studies. In the more recent literature, 'sex' indicates biological differences between men and women, and 'gender' refers to role expectations influenced by a variety of factors $(33,34)$. Both of these variables have been specified

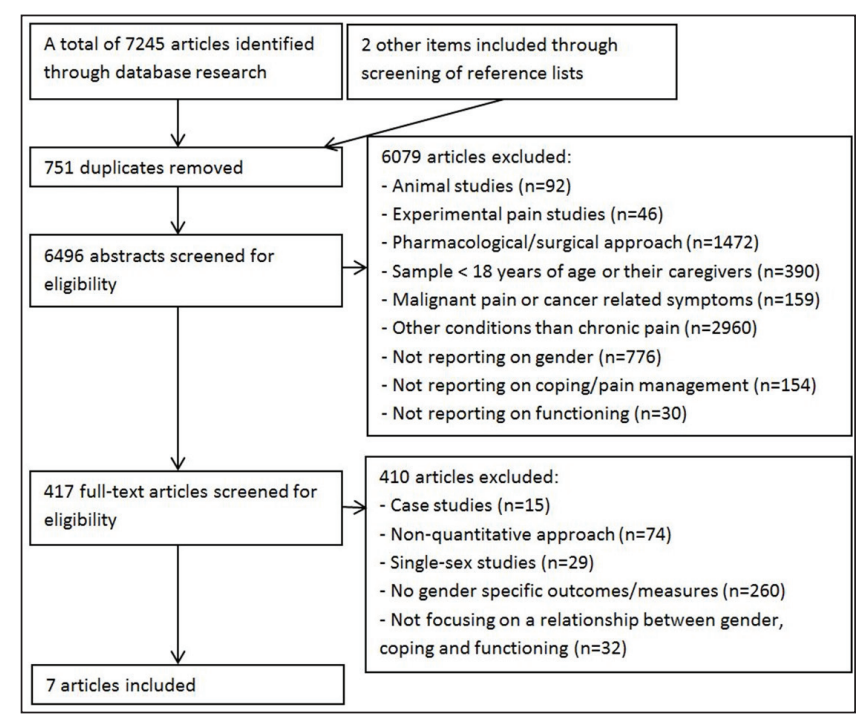

Figure 1) The process of study inclusion

in this systematic review to conduct a comprehensive literature search. For the purpose of the present study, the term 'gender' will be adopted, unless otherwise specified in relation to particular literature.

Additionally, database-specific $\mathrm{MeSH}$ terms and headings were included to improve the search results. Using these search terms, 7245 articles were identified, and an additional two articles were retrieved from manual screening of reference lists and bibliographies.

\section{Inclusion and data extraction process}

The Preferred Reporting Items for Systematic Reviews and MetaAnalyses (PRISMA) guidelines and Participants, Interventions, Comparisons, Outcomes and Study design (PICOS) elements (32) were used to guide the present systematic review through all stages: planning, evaluating articles, conducting the research and writing the manuscript. After obtaining articles through the initial search process, one reviewer screened abstracts and full-text articles for eligibility. An abstract screening form and a full-text screening form were specifically designed for this purpose, based on previously described criteria for inclusion in the present systematic review. Any discrepancies that arose during the screening process were discussed by the team of three researchers until conciliation was reached. In the next step, two reviewers independently assessed potential articles for suitability for inclusion using another custom designed form. One reviewer extracted the data and tabulated them; a second reviewer verified the accuracy of the table with attention to each article. Study characteristics can be found in Table 1. Due to the small number of studies, and the variety of research designs, diagnoses and outcome measures evidenced in the studies, the focus of the present systematic review was on describing the available literature in the form of qualitative synthesis rather than a meta-analysis (32).

\section{Methodological quality assessment}

The methodological quality of each of the obtained studies was assessed using a modified version of the original Downs and Black Checklist (35) (Appendix 1). Reporting style, as outlined in the checklist, as well as external validity, internal validity and statistical power were assessed by two independent reviewers. Disagreements were resolved through objective discussion. No articles were excluded based on methodological quality.

\section{Study selection}

\section{RESULTS}

The process of study inclusion is presented in the flow diagram in Figure 1. A total of 7245 studies were identified through database searches and two additional studies were retrieved by the screening 
TABLE 1

Study characteristics

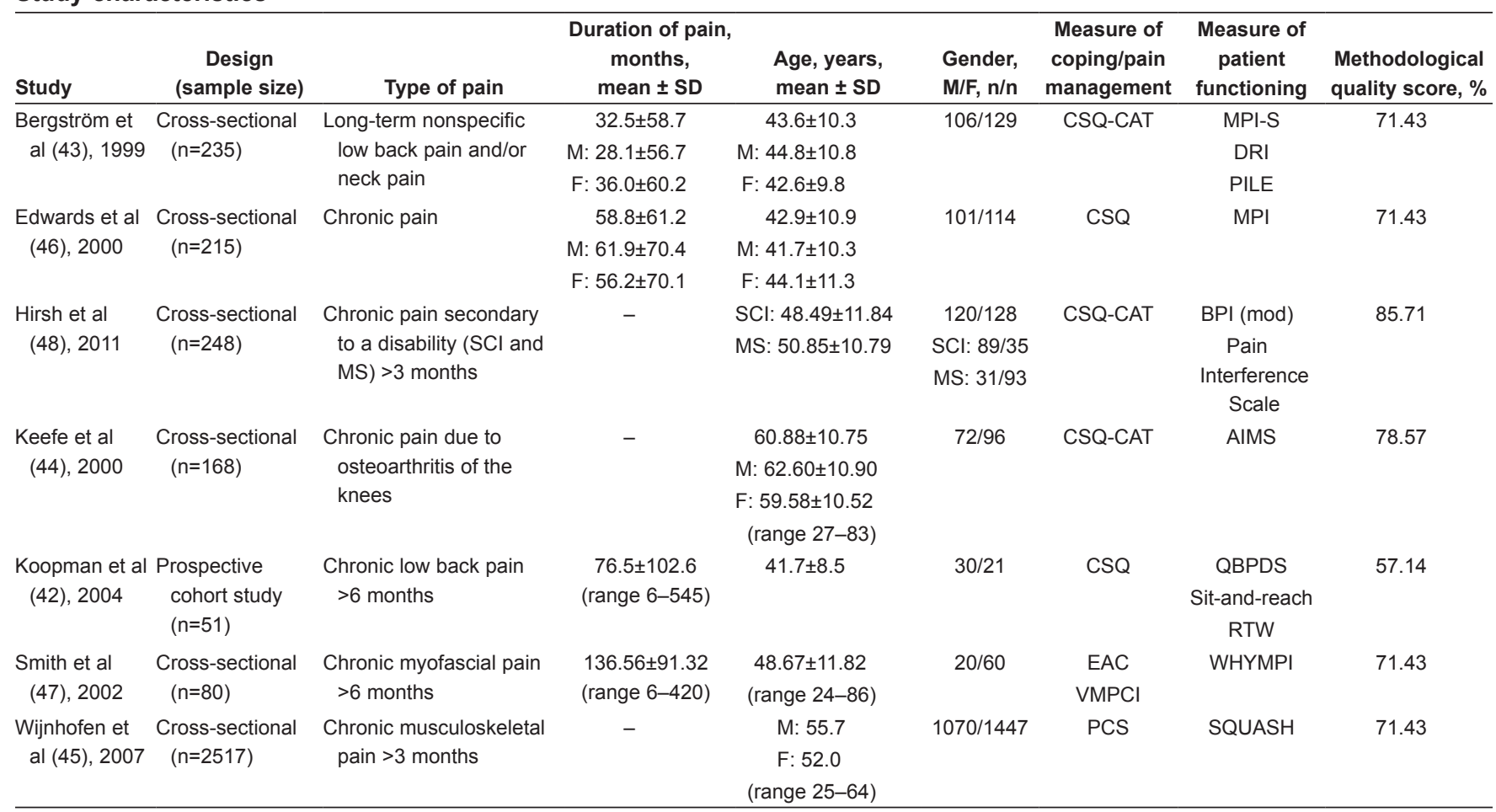

AIMS Arthritis Impact Measurement Scale; BPI Brief Pain Inventory; CSQ Coping Strategies Questionnaire; CSQ-CAT Catastrophizing Subscale of the CSQ; DRI Disability Rating Index; EAC Emotional Approach Coping Scale; F Female; M Male; MPI Multidimensional Pain Inventory; MPI-S MPI - Swedish Version; MS Multiple Sclerosis; PCS Pain Catastrophizing Scale; PILE Progressive Isoinertial Lifting Evaluation; QBPDS Quebec Back Pain Disability Scale; RTW Return to Work; SCI Spinal Cord Injury; SQUASH Short Questionnaire to Assess Health-Enhancing Physical Activity; VMPCI Vanderbilt Multidimensional Pain Coping Inventory; WHYMPI The West-Haven-Yale Multidimensional Pain Inventory

of bibliographies of relevant articles. All were published documents. After the removal of 751 duplicates, the remaining 6496 articles were subject to further examination. Screening of the abstracts resulted in 6079 studies being excluded because of ineligibility for this systematic review. The full texts of the remaining 417 articles were analyzed in detail. This resulted in further exclusions, as detailed in Figure 1. The remaining seven studies met all of the inclusion criteria and were included in the present systematic review.

\section{Study characteristics}

The characteristics of the included studies are presented in Table 1. The majority of studies were cross-sectional in nature $(n=6)$, with one study using a prospective research design. Articles were published between 1999 and 2011. The participants' pain duration ranged from six to 545 months, although three studies did not report on mean pain duration. Most studies $(n=5)$ focused on a sample with a mean age $<50$ years. In the three studies that included details on participants' age range, the range was 24 to 86 years. Four of the included studies reported separate gender-specific details on age and/or pain duration.

The type of pain and the source of participants differed across studies. One study included individuals with chronic musculoskeletal pain, while another included participants with chronic myofascial pain. Two studies reported on adults with chronic back or neck pain and another involved a group of patients with heterogeneous chronic pain complaints seen at a pain centre. One study involved people with osteoarthritis. The final study involved individuals who lived with either multiple sclerosis or spinal cord injury and had concomitant chronic pain. Five studies assessed adults who were attending particular treatment programs, while the remaining two assessed adults who were community dwelling and not in active search of pain treatment at the time of assessment.

The total ratio of women to men who participated in these studies was 1995:1519. Two studies examined small sample sizes of between
50 and 100 participants, one sample size was between 150 and 200, three were between 200 and 250, and one had $>2500$ participants.

Of the seven included studies, the majority $(n=5 ; 71.43 \%)$ used the Coping Strategies Questionnaire (CSQ) (36) as the measure of coping, with three of these using only the Catastrophizing Subscale of the CSQ. Five different measures of functioning were used in these articles. The most commonly used, in three studies, was the Multidimensional Pain Inventory Pain Interference Scale (MPI) (37). All other measures were used just once: the Brief Pain Inventory - Pain Interference Scale (BPI) (38), the Quebec Back Pain Disability Scale (QBPDS) (39), the Arthritis Impact Measurement Scale (AIMS) (40) and the Short Questionnaire to Assess Health-Enhancing Physical Activity (SQUASH) (41) (for further information on measurements used, please see references $36-41$ ). Additionally, $71.43 \%$ and $14.29 \%$ of the studies included measures of depression and anxiety, respectively.

Methodological quality analysis

The outcomes of the methodological quality analysis are presented in Table 1. Six of the studies were of high quality, with scores $>70 \%$ on the modified Downs and Black Checklist. The study by Koopman et al (42), with a score of $57.14 \%$, was considered to be of moderate quality. Three items of the modified Downs and Black Checklist were consistently rated poorly across the studies: items 9 and 10 (assessing external validity) and item 7 (reporting on actual probability values). In addition, item 14 (power estimations) was not consistently reported across the seven studies.

Gender and functioning in chronic pain In three of the high-quality studies, significant differences in functioning between men and women with chronic pain were reported. In all three cases, women were functionally impacted more than men. The measurement of functioning differed in each of these studies, with 
TABLE 2

Summary of the identified associations (including effect sizes)

\section{Associations between coping \\ and functioning}

'Catastrophizing' and lower

levels of functioning

\section{Studies}

Bergström et al (43), 1999

Hirsh et al (48), 2011

Keefe et al (44), 2000

Wijnhofen et al (45), 2007

\section{'Reinterpreting pain sensations' Koopman et al (42), and higher levels of 2004 functioning}

Emotional Approach Coping and Smith et al (47), 2002 higher levels of functioning

Presence of emotional states (eg, anxiety and depression) are associated with coping and functioning

\section{Associations between coping and functioning}

Catastrophizing and interference in activities of daily living were more strongly correlated for women (Pearson's correlation coefficient: $0.44 ; \mathrm{P}<0.001)$ than men $(0.24 ; \mathrm{P}<0.05)$

The association between gender and catastrophizing approached significance for pain interference $(\beta=0.28 ; P=0.06)$. Women with greater catastrophizing were slightly stronger associated with greater pain interference $(R=0.50 ; P<0.001)$ when compared with men $(R=0.42 ; P<0.001)$

Catastrophizing appeared to function as a mediator in the relationship between gender and painrelated outcomes (including physical disability). It has been found that women were using catastrophizing significantly more often (mean $[ \pm$ SD] $7.01 \pm 6.95$ and $3.08 \pm 4.48$ ) and also experienced greater physical disability levels $(1.95 \pm 1.00$ and $1.45 \pm 0.87)$ compared with men, respectively High levels of catastrophizing were associated with poorer levels of functioning in men $(1.74[95 \% \mathrm{Cl}$ 1.31-2.31]; $\mathrm{P} \leq 0.05)$ and women (1.66 [95\% Cl 1.33-2.07]; $\mathrm{P} \leq 0.05)$. The difference between the genders, however, has not been found to be statistically significant. Women, however, have been found to engage in this coping pattern more often $(P<0.05)$. Men engaging in catastrophizing coping

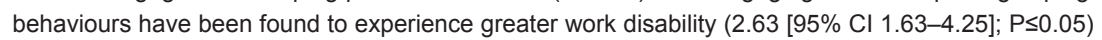
when compared with women (1.35 [95\% Cl 0.89-2.04]; not statistically significant)

Male gender and engagement in 'reinterpretation of pain sensations' were factors related to return to work within 12 month (OR for sex in multiple logistic regression analyses: 1.00 and 0.10 )

Men engaging in Emotional Approach Coping experienced lower physical impairment. This association was not found for women (partial correlation coefficients -0.30 and 0.06 , respectively)

Edwards et al (46), 2000 Men with high anxiety levels experienced greater pain interference when compared to men with low anxiety levels $(P<0.05)$. This association was not found for women and did not appear to be mediated by coping strategies.
Bergström et al (43) using the MPI Pain Interference Scale among other measurements, Keefe et al (44) using the AIMS, and Wijnhoven et al (45) using a dichotomous low/moderate to high scale of physical functioning (41).

Three studies (all of high quality) found no significant differences in functioning between men and women with chronic pain. Measures used to assess functioning in this subset of studies included the MPI Pain Interference Scale, which was used by both Edwards et al (46) and Smith et al (47), and a modified version of the BPI Interference Scale, which was used by Hirsh et al (48).

In the remaining study (of moderate quality), Koopman et al (42) did not consider gender differences in disability despite using the Dutch version of the Quebec Back Pain Disability Scale. However, they reported on gender differences with respect to return to work, with men having better outcomes.

\section{Gender and coping}

In four of the seven studies (57.14\%), differences were found in pain coping strategies used by men and women with chronic pain. These four studies specifically examined the associations among catastrophizing, pain intensity and gender. In three of these four studies (43-45), women in pain had higher rates of catastrophizing than men in pain, with Bergström et al (43) and Keefe et al (44) using the Catastrophizing Subscale of the CSQ, and Wijnhoven et al (45) using a Dutch version of the Pain Catastrophizing Subscale. In the fourth study, Hirsh et al (48) reported a trend for men in pain to exhibit higher catastrophizing than women in pain $(\mathrm{P}=0.09)$. This study also used the Catastrophizing Subscale of the CSQ.

In contrast, the fifth study, by Smith et al (47), found no significant differences between men and women on the Emotional Approach Coping (EAC) scale, or on any of the Vanderbilt Multidimensional Pain Coping Inventory scales. Meanwhile, in the sixth study, Edwards et al (46) found no significant differences between the pain coping strategies used by men and women in chronic pain using the CSQ.

In the one longitudinal treatment study, Koopman et al (42) found that treatment significantly decreased the use of catastrophizing and praying and hoping strategies of the sample, and increased the use of reinterpreting coping strategies across the group who participated in a multidisciplinary back pain program. The CSQ scales were used in this study. They did not, however, find any interactions for gender differences on these pain coping strategies across the three time points.

Gender, function and coping

All of the included studies reported some findings about how all three of the variables of interest - ie, gender, coping strategy use and functioning- were linked. These are summarized in Table 2. Using Structural Equation Modeling, Keefe et al (44) found that catastrophizing appeared to mediate the relationship between gender and pain-related outcomes including physical disability. Higher levels of catastrophizing and higher physical disability were found in women. Similarly, a stronger correlation between catastrophizing and interference for women than men was reported by Bergström et al (43). Hirsh et al (48) found that the interaction between catastrophizing and gender approached significance for pain interference $(\mathrm{P}=0.06)$; that is, while they found a significant association between catastrophizing and pain interference for both genders, this was slightly stronger for women. Wijnhoven et al (45) also found a significant association between increased pain catastrophizing and poorer functioning in both men and women. Nevertheless, they also found that women used this coping attempt to a greater extent compared with men. Additionally, the authors found that catastrophizing was associated with greater work disability for men only.

Koopman et al (42) used multiple regression analysis to determine factors that predicted a successful return to work after treatment, and found that being male, younger age, lower levels of functional disability and increased use of the coping strategy 'reinterpretation of pain sensations' predicted increased return to work within 12 months.

Smith et al (47) found that increased use of EAC in men in pain tended to be associated with less life interference on the MPI Pain Interference Scale, although this association did not reach significance. No such association was found for women. With 60 women and 20 men in their study, the authors posited that the limited power to detect 
significant gender differences may have affected their results. This study did, however, find that increased use of EAC was associated with better functioning for men. Edwards et al (46) found that men who were highly anxious had greater pain interference than men with low anxiety. This association was not found for women and was unrelated to the use of specific coping strategies in both genders. Furthermore, there were significant correlations for men, between high levels of anxiety and catastrophizing, high levels of anxiety and praying and hoping, and high levels of anxiety and reduced use of coping self-statements. In women, higher levels of anxiety were associated with greater engagement in praying and hoping and higher levels of catastrophizing.

\section{DISCUSSION}

The present systematic review was conducted to achieve two goals: to review the current knowledge about associations among gender, coping patterns and functioning in the face of chronic pain; and to provide directions for further research and clinical approaches. It is, to our knowledge, the first systematic review to have examined gender, coping and functioning in people with chronic pain. The inclusion of more than one synonym for the keywords and a very detailed data screening process makes it unlikely that relevant work has been overlooked.

From 7247 titles identified, 6496 articles were initially retrieved for review. Of the articles that met the inclusion criteria, only seven were retained for inclusion in the present systematic review. Of these articles, six were of high methodological quality, while the remaining article was of moderate methodological quality. However, the limited number of articles and the variations in the measures and study designs used limit the capacity to draw definitive conclusions. While an examination of these seven studies does not permit conclusions to be made on the relationships among gender, coping strategy use and functioning in people with chronic pain, it does provide some preliminary findings, which can help inform further research.

Tentative conclusions that can be drawn are that there appear to be some gender-specific differences in the use of specific types of coping strategies, and in the influence of these strategies on functioning in men and women in chronic pain. With regard to catastrophizing, most studies reported associations with poorer functioning for both genders. While there was a trend for these associations to be stronger for women than for men, most of these analyses did not reach significance. This general lack of differences between the genders in relation to the association between catastrophizing and functioning appears to be in contradiction with the expectation that women experience lower functioning, related to the consistent finding in the coping literature and in most articles in the present review that women use this coping strategy to a greater extent. Further research involving larger sample sizes to obtain more significant results would be needed to address this apparent discrepancy.

Pain expression - not only through language, but also through nonverbal expression - is an important aspect of personal protection and pain management, but also serves as a medium of social communication $(12,33)$. The stronger engagement of women in catastrophizing as a coping strategy could be explained on biological grounds. For example, the hormone oxytocin, which women produce more than men, is released in stressful situations and has been found to be associated with seeking social support (49). Because catastrophizing coping behaviours are often discussed as a medium of communication (11), this way of coping is more applicable to the general coping structure of women. On the other hand, gender role socialization may also be associated with women's greater engagement in emotion-focused coping behaviours such as catastrophizing. From an early age, women are socialized to express their emotions and seek social support, while men are more likely to be discouraged from doing so $(49,50)$. In general, emotional expression has been strongly linked with social interactions and gender-specific relationship patterns, especially with regard to displaying vulnerability (13). It is, therefore, possible that both innate and learned aspects are associated with gender-specific engagement in coping behaviours and associated functioning.
It has further been found in the present review that women experience greater interference from pain on their functioning, which was, in part, associated with greater engagement in catastrophizing. Therefore, it is possible, as opined by Keefe et al (44), that clinical management of women with chronic pain may require greater attention to reducing reliance on catastrophizing. Keefe et al suggested that women, in particular, may benefit from 'cognitive restructuring' to decrease their catastrophic thinking, with a subsequent increase in functional ability. However, given the findings of the present systematic review, not only women, but also men, may benefit from this intervention.

It is important to consider the possibility that women experience greater functional interference from pain than men, independent of the specific coping strategies used. This may be explained by greater, or at least different, social role expectations for women. Bergström et al (43) raised this issue, noting the wider and more numerous life roles of women. For example, women with chronic pain may be expected to participate in "paid work, child-care, household activities and social relationships" (43). If they develop a chronic pain condition, they may prioritize their family roles and responsibilities over work-related roles (51). This aspect needs to be considered with regard to implications for results on functional measures in previous research and highlights the need for consideration in future studies. In contrast, men may only have one major role, that of paid work. If this was the case, then clinical management for women may be directed toward acquiring additional support to attend to their life roles, such as task reassignment within families or acquisition of additional, paid help.

Another tentative recommendation to emerge from the present review is that men with chronic pain should be introduced to a wider array of coping strategies, such as emotion-focused coping, which may assist them to obtain better functional outcomes. The findings by Smith et al (47) suggested positive associations between the use of EAC and less physical impairment for men. This suggests that men with chronic pain may benefit from training in the use of emotionfocused coping strategies. The results that men and women did not differ in their use of EAC appear to contradict the common belief that women use emotion-focused coping strategies more often than men, as reported by Unruh (21). Understanding this discrepancy could provide essential insights into fundamental differences in pain behaviour between men and women. In particular, although men tend to engage in emotion-focused coping strategies less often, they appear to experience better functional outcomes when doing so. Up-skilling men in the use of emotion-focused strategies may provide them with an additional tool to manage their pain.

The other coping strategy found to be associated with improved functioning was the use of reinterpreting pain sensations. Men in the respective study were also more likely to be in the group with improved function after rehabilitation. Hence, women may benefit from learning more about re-interpreting pain sensations as a coping strategy.

Other important factors that may impact upon an individual's pain experience, coping and functioning include emotional states such as depression and anxiety $(24,52)$. While not the focus of the current review, five $(71.43 \%)$ and one $(14.29 \%)$ of the studies included in the present systematic review used measures of depression and anxiety, respectively. In general, women are believed to be more vulnerable to both depression and anxiety than men (24). Furthermore, women with high levels of depression reported higher degrees of disability than men (24). While women with chronic pain conditions seemed more likely to experience higher levels of depression than men (51), men were more likely to experience anxiety. Edwards et al (46) found that men with higher anxiety levels had increased pain, increased pain interference and decreased activity when compared with men with lower anxiety levels, while no such association has been found for women. This suggests that future studies should include the variables of depression and anxiety, given potential gender differences in these variables, which may mask gender-related coping differences. Clinically, it may be important to 
initially assess and treat emotional states, before aiming to modify gender-related coping patterns. Individuals may be able to achieve greater improvement of their functional ability, when interventions targeting emotional states and coping factors are stepwise included in treatment programs in clinical practice.

Chronicity of the pain may also be a factor to consider when evaluating coping strategies and functioning in the light of gender. Keefe et al (44) theorized that gender may not moderate the effects on functioning as strongly in a sample of individuals with a higher level of disability. Longer pain duration is related to greater levels of disability, and more maladaptive coping strategies are observed at such times (53). It is possible that more prominent gender differences in coping may be observed in a sample of individuals with acute pain, or among individuals living with recently acquired chronic pain. Furthermore, sample characteristics, such as whether the participants are in active treatment and the types of pain conditions, may have an important influence on the findings and should, therefore, be taken into consideration and reported in detail in future research.

The review was hampered by the use of multiple measures of the same constructs. Greater consistency in the use of particular outcome measures across studies would be useful to enable a more direct comparison of results across studies. The IMMPACT guidelines (54) can provide some guidance, but it must be noted that IMMPACT did not suggest uniform measurement of the coping construct. The MPI Pain Interference Scale or the BPI Pain Interference Scale are both IMMPACT-endorsed scales.

It is possible that the present systematic review is affected by publication bias, resulting in a reduced number of studies due to the nonpublication of nonsignificant findings. In addition, mostly self-report questionnaires were used in studies examining coping strategies and levels of functioning and disability. This could be seen as a limitation because no objective measures were used, but can also be seen as a strength, enabling examination of the subjectively perceived pain experience. Furthermore, the small number of male participants in some of the studies, while consistent with prevalence rates, may limit the chances of detecting gender differences.

Consideration of these articles collectively provides guidance for the areas which warrant further attention. The present body of literature is relatively small, and consists largely of cross-sectional studies. Further research using longitudinal or randomized controlled research designs are important to demonstrate predictive relationships $(30,31)$. For example, further investigation of the influence of gender differences in the use of specific coping patterns with regard to return to work, in a randomized controlled trial or longitudinal design, would be particularly helpful to inform future efforts to reduce the large number of people absent from work due to a chronic pain condition (6). While it is acknowledged that a range of personal and environmental factors may affect coping with pain, all studies have focused only on personal coping strategies. This suggests the need for further research in relation to gender differences in environmental coping strategies (eg, availability of support) and associated functioning. It would also be interesting to examine why EAC was only associated with lower levels of physical impairment for men, even though women engage in emotion-focused coping behaviours more often than men. Additionally, studies with greater sample sizes, and possibly a matched number of male and female participants, would greatly improve the chances of detecting gender differences. Future research on the interrelation among gender, coping and functioning is essential for the development of individually tailored interventions that meet the specific needs of both men and women experiencing chronic pain.

\section{CONCLUSIONS}

In the present systematic review, preliminary evidence for associations among gender, coping patterns and functioning in people experiencing chronic pain was obtained. The findings support the proposition that gender and related utilization of coping strategies are associated with functioning in individuals living with chronic pain; however, limitations in this literature were also observed. These results highlight the importance of future research with regard to gender-specific assessment and treatment approaches to meet the specific needs of men and women in chronic pain.

ACKNOWLEDGEMENTS: The authors acknowledge the contribution of Ms Rachel Feeney to the data analysis stage of this study.

\section{APPENDIX 1 \\ Modified Downs and Black Checklist}

Score $(\mathrm{Yes}=1, \mathrm{No}=0)$

\section{Reporting}

1. Is the hypothesis/aim/objective of the study clearly described?

2. Are the main outcomes to be measured clearly described in the Introduction or Methods section?

3. Are the characteristics of the patients included in the study clearly described? (inclusion and/or exclusion criteria)

4. Is the approach to coping and activity measure clearly described?

5. Are the main findings of the study clearly described?

6. Does the study provide estimates of random variability in the data for the main outcomes (eg, interquartile range for nonnormally distributed data; standard error, standard deviation, or confidence intervals for normally distributed data)?

7. Have the actual probability values been reported (eg, 0.035 rather than $<0.05$ ) for the main outcomes except where the probability value is less than 0.001 ?

\section{External validity}

8. Were the subjects asked to participate in the study representative of the entire population from which they were recruited?

9. Were those subjects who were prepared to participate representative of the entire population from which they were recruited?

10. Were the staff, places, and facilities where patients were treated representative of the treatment the majority of patients receive?

Internal validity

11. If any of the results of the study based on "data dredging" (analysis that had not been planned at the outset of the study), was this made clear?

12. Were the statistical tests used to access the main outcomes appropriate?

13. Were the main outcome measures used accurate (valid and reliable)?

Power

14. Did the study report on statistical power?

Total 


\section{REFERENCES}

1. Blyth FM, March LM, Brnabic AJ, Jorm LR, Williamson M, Cousins MJ. Chronic pain in Australia: A prevalence study. Pain 2001;89:127-34.

2. Johannes CB, Le TK, Zhou X, Johnston JA, Dworkin RH. The prevalence of chronic pain in United States adults: Results of an Internet-based survey. J Pain 2010;11:1230-9.

3. Crosby FE, Colestro J, Ventura MR, Graham K. Survey of pain among veterans in Western New York. Pain Manag Nurs 2006;7:12-22.

4. Ericsson M, Poston WS, Linder J, Taylor JE, Haddock CK, Foreyt JP. Depression predicts disability in long-term chronic pain patients. Disabil Rehabil 2002;24:334-40.

5. Kroenke K, Krebs EE, Bair MJ. Pharmacotherapy of chronic pain: A synthesis of recommendations from systematic reviews. Gen Hosp Psychiatry 2009;31:206-19.

6. Katz WA. Musculoskeletal pain and its socioeconomic implications. Clin Rheumatol 2002;21:S2-S4.

7. Liechtenstein MJ, Dhanda R, Cornell JE, Escalante A, Hazuda HP. Disaggregating pain and its effect on physical functional limitations. J Gerontol A Biol Sci Med Sci 1998;53A:M361-M71.

8. Blyth FM, March LM, Nicholas MK, Cousins MJ. Chronic pain, work performance and litigation. Pain 2003;103:41-7.

9. Jensen MP, Turner JA, Romano JM, Karoly P. Coping with chronic pain: A critical review of the literature. Pain 1991;47:249-83.

10. Peres MP, Lucchetti G. Coping strategies in chronic pain. Curr Pain Headache Rep 2010;14:331-8.

11. Sullivan MJ, Martel MO, Tripp D, Savard A, Crombez G. The relation between catastrophizing and the communication of pain experience. Pain 2006;122:282-8.

12. Craig KD. The social communication model of pain. Can Psychol 2009;50:22-32.

13. Vigil JM. A socio-relational framework of sex differences in the expression of emotion. Behav Brain Sci 2009;32:375-428.

14. Lanes TC, Gauron EF, Spratt KF, Wernimont TJ, Found EM, Weinstein JN. Long-term follow-up of patients with chronic back pain treated in a multidisciplinary rehabilitation program. Spine 1995;20:801-6.

15. Deardorff WW, Rubin HS, Scott DW. Comprehensive multidisciplinary treatment of chronic pain: A follow-up study of treated and non-treated groups. Pain 1991;45:35-43.

16. Keogh E, McCracken LM, Eccleston C. Do men and women differ in their response to interdisciplinary chronic pain management? Pain 2005; 114:37-46.

17. Ciccone GK, Holdcroft A. Drugs and sex differences: A review of drugs relating to anaesthesia. Br J Anaesth 1999;82:255-65.

18. Fillingim RB, Gear RW. Sex differences in opioid analgesia: Clinical and experimental findings. Eur J Pain 2004;8:413-25.

19. Jensen IB, Bergstrom G, Ljungquist T, Bodin L, Nygren AL. A randomized controlled component analysis of a behavioral medicine rehabilitation program for chronic spinal pain: Are the effects dependent on gender? Pain 2001;91:65-78.

20. Krogstad BS, Jokstad A, Dahl BL, Vassend O. The reporting of pain, somatic complaints, and anxiety in a group of patients with TMD before and 2 years after treatment: Sex differences. J Orofac Pain 1996;10:263-9.

21. Unruh AM. Gender variations in clinical pain experience. Pain 1996;65:123-67.

22. Keefe FJ, Caldwell DS, Martinez S, Nunley J, Beckham J, Williams DA. Analyzing pain in rheumatoid arthritis patients. Pain coping strategies in patients who have had knee replacement surgery. Pain 1991;46:153-60.

23. Arnow BA, Blasey CM, Constantino MJ, et al. Catastrophizing, depression and pain-related disability. Gen Hosp Psychiatry 2011;33:150-6.

24. Keogh E, McCracken LM, Eccleston C. Gender moderates the association between depression and disability in chronic pain patients. Eur J Pain 2006;10:413-22.

25. Unruh AM, Ritchie J, Merskey H. Does gender affect appraisal of pain and pain coping strategies? Clin J Pain 1999;15:31-40.

26. Edwards R, Haythornthwaite JA, Sullivan MJ, Fillingim RB. Catastrophizing as a mediator of sex differences in pain: Differential effects for daily pain versus laboratory-induced pain. Pain 2004;111:335-41.

27. Jensen I, Nygren A, Gamberale F, Goldie I, Westerholm P. Coping with long-term musculoskeletal pain and its consequences: Is gender a factor? Pain 1994;57:167-72.
28. Greenspan JD, Craft RM, LeResche L, et al. Studying sex and gender differences in pain and analgesia: A consensus report. Pain 2007;132(Suppl 1):S26-S45.

29. Fillingim RB, King CD, Ribeiro-Dasilva MC, Rahim-Williams B, Riley JL 3rd. Sex, gender, and pain: A review of recent clinical and experimental findings. J Pain 2009;10:447-85.

30. Altman DG, Schulz KF, Moher D, et al. The revised CONSORT statement for reporting randomized trials: Explanation and elaboration. Ann Intern Med 2001;134:663-94.

31. Cole DA, Maxwell SE. Testing mediational models with longitudinal data: Questions and tips in the use of Structural Equation Modeling. J Abnorm Psychol 2003;112:558-77.

32. Liberati A, Altman DG, Tetzlaff J, et al. The PRISMA statement for reporting systematic reviews and meta-analyses of studies that evaluate health care interventions: Explanation and elaboration. Ann Intern Med 2009;151:W65-W94.

33. Bernardes SF, Keogh E, Lima ML. Bridging the gap between pain and gender research: A selective literature review. Eur J Pain 2008;12:427-40.

34. Robinson ME, Riley JL 3rd, Myers CD, et al. Gender role expectations of pain: Relationship to sex differences in pain. J Pain 2001;2:251-7.

35. Downs SH, Black N. The feasibility of creating a checklist for the assessment of the methodological quality both of randomised and non-randomised studies of health care interventions. J Epidemiol Community Health 1998;52:377-84.

36. Rosenstiel AK, Keefe FJ. The use of coping strategies in chronic low back pain patients: Relationship to patient characteristics and current adjustment. Pain 1983;17:33-44.

37. Kerns RD, Turk DC, Rudy TE. The West Haven-Yale Multidimensional Pain Inventory (WHYMPI). Pain 1985;23:345-56.

38. Keller S, Bann CM, Dodd SL, Schein J, Mendoza TR, Cleeland CS. Validity of the Brief Pain Inventory for use in documenting the outcomes of patients with noncancer pain. Clin J Pain 2004;20:309-18.

39. Schoppink LE, van Tulder MW, Koes BW, Beurskens SA, de Bie RA. Reliability and validity of the Dutch adaptation of the Quebec Back Pain Disability Scale. Phys Ther 1996;76:268-75.

40. Meenan RF, Gertman PM, Mason JH. Measuring health status in arthritis. Arthritis Rheum 1980;23:146-52.

41. Wendel-Vos GC, Schuit AJ, Saris WH, Kromhout D. Reproducibility and relative validity of the short questionnaire to assess health-enhancing physical activity. J Clin Epidemiol 2003;56:1163-9.

42. Koopman FS, Edelaar M, Slikker R, Reynders K, van der Woude LH, Hoozemans MJ. Effectiveness of a multidisciplinary occupational training program for chronic low back pain: A prospective cohort study. Am J Phys Med Rehabil 2004;83:94-103.

43. Bergström KG, Jensen IB, Linton SJ, Nygren AL. A psychometric evaluation of the Swedish version of the Multidimensional Pain Inventory (MPI-S): A gender differentiated evaluation. Eur J Pain 1999;3:261-73.

44. Keefe FJ, Lefebvre JC, Egert JR, Affleck G, Sullivan MJ, Caldwell DS The relationship of gender to pain, pain behavior, and disability in osteoarthritis patients: The role of catastrophizing. Pain 2000;87:325-34.

45. Wijnhoven HA, de Vet HC, Picavet HS. Sex differences in consequences of musculoskeletal pain. Spine 2007;32:1360-7.

46. Edwards R, Augustson EM, Fillingim RB. Sex-specific effects of pain-related anxiety on adjustment to chronic pain. Clin J Pain 2000;16:46-53.

47. Smith J, Lumley M, Longo D. Contrasting emotional approach coping with passive coping for chronic myofascial pain. Ann Behav Med 2002;24:326-35.

48. Hirsh AT, Bockow TB, Jensen MP. Catastrophizing, pain, and pain interference in individuals with disabilities. Am J Phys Med Rehabil 2011;90:713-22.

49. Tamres LK, Janicki D, Helgeson VS. Sex differences in coping behavior: A meta-analytic review and an examination of relative coping. Pers Soc Psychol Rev 2002;6:2-30.

50. Range L, Jenkins S. Who benefits from Pennebaker's expressive writing paradigm? Research recommendations from three gender theories. Sex Roles 2010;63:149-64. 
51. Adams H, Thibault P, Davidson N, Simmonds M, Velly A, Sullivan MJ. Depression augments activity-related pain in women but not in men with chronic musculoskeletal conditions. Pain Res Manag 2008;13:236-42.

52. Hall AM, Kamper SJ, Maher CG, Latimer J, Ferreira ML, Nicholas MK. Symptoms of depression and stress mediate the effect of pain on disability. Pain 2011;152:1044-51.
53. Sullivan MJ, Sullivan ME, Adams HM. Stage of chronicity and cognitive correlates of pain-related disability. Cogn Behav Ther 2002;31:111-8,

54. Dworkin RH, Turk DC, Wyrwich KW, et al. Interpreting the clinical importance of treatment outcomes in chronic pain clinical trials: IMMPACT recommendations. J Pain 2008;9:105-21. 


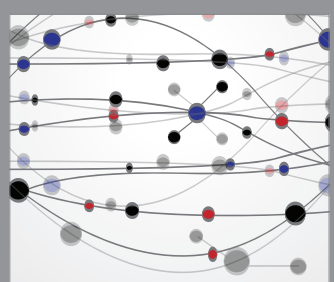

The Scientific World Journal
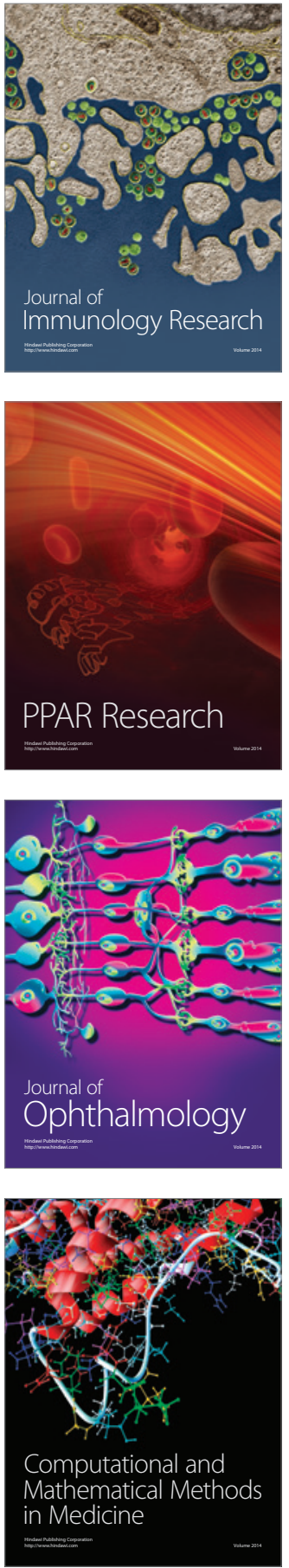

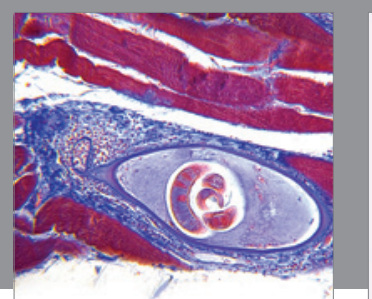

Gastroenterology Research and Practice

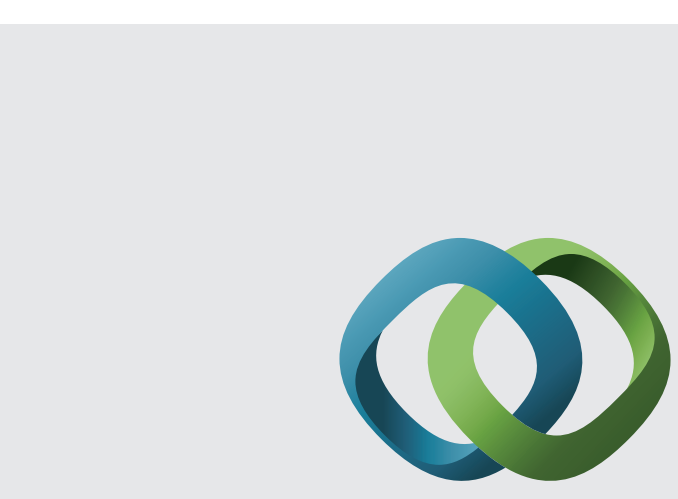

\section{Hindawi}

Submit your manuscripts at

http://www.hindawi.com
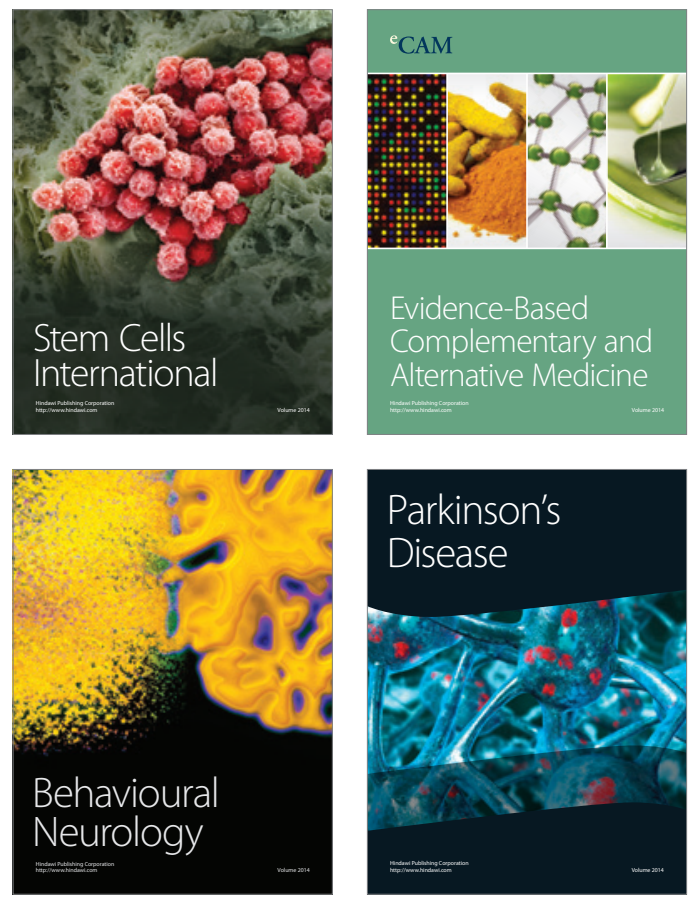
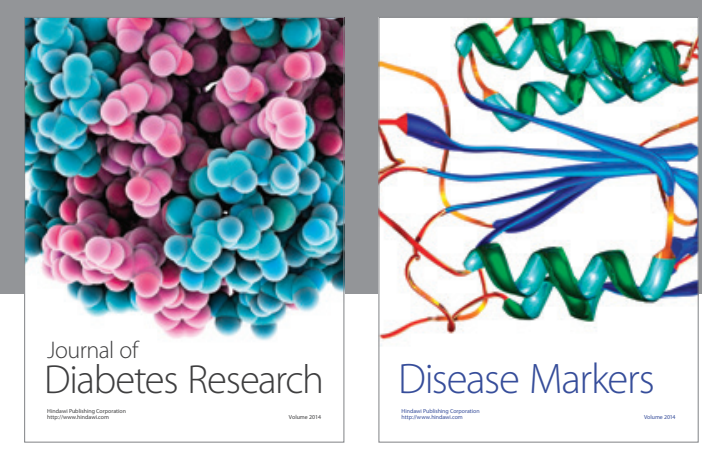

Disease Markers
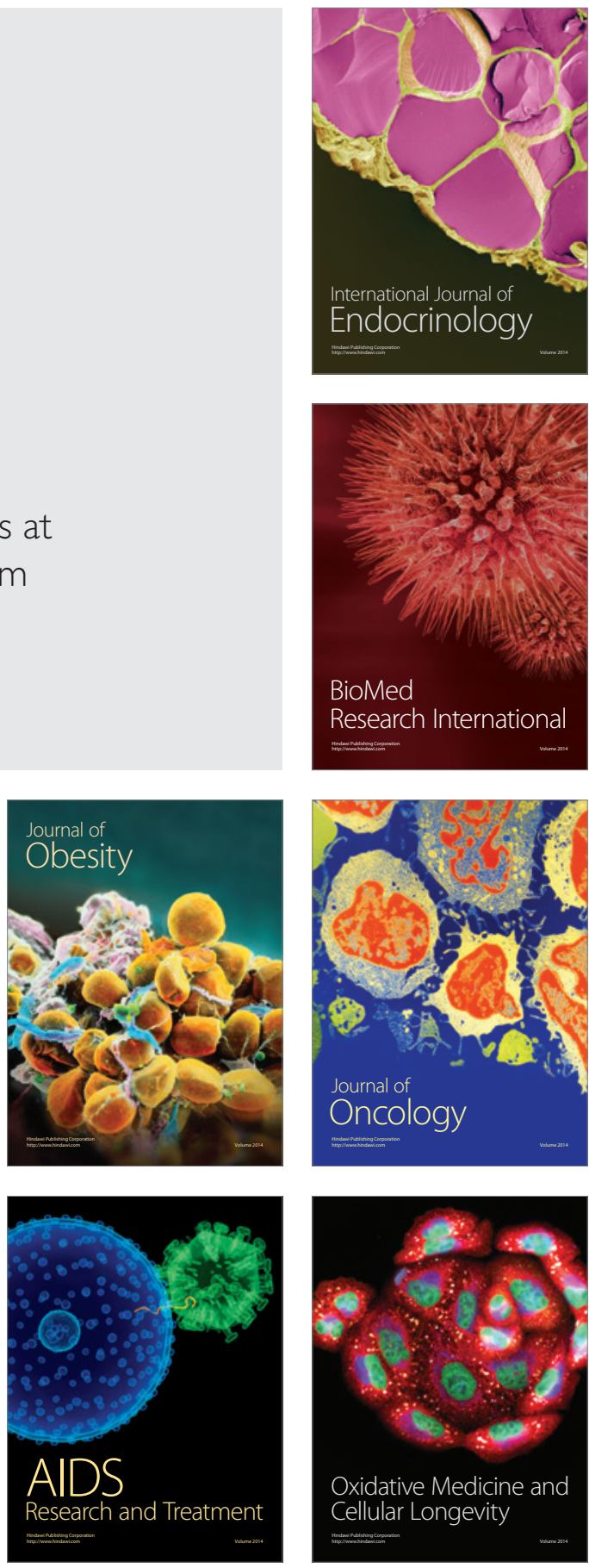